ARTIGO N²

RODOANEL, ANEL VIÁRIO OU AVENIDAS PERIMETRAIS?

BELTWAY, RING ROAD OR PERIMETER AVENUES?

JOSÉ BENTO FERREIRA 


\title{
RODOANEL, ANEL VIÁRIO OU AVENIDAS PERIMETRAIS?
}

\author{
José Bento FerReira* \\ *Engenheiro Civil graduado pela Universidade de Taubaté (UNITAU), Mestre e Doutor pela \\ Faculdade de Arquitetura e Urbanismo da Universidade de São Paulo (FAUUSP). \\ Docente do Departamento de Engenharia Civil do Campus de Guaratinguetá da \\ Universidade Estadual Paulista "Júlio de Mesquita Filho"(UNESP)
}

\begin{abstract}
RESUMO
O artigo tem como objetivo a discussão da funcionalidade de um dispositivo de transporte rodoviário, o anel viário, com suas variações operacionais, e, utilizando um exemplo, o Rodoanel Mário Covas, implantado na Região Metropolitana da Grande São Paulo, mostrar como a adoção de um modelo operacional inadequado pode comprometer o seu desempenho e degradar o ambiente construído.
\end{abstract}

Palavras-chave: Anel viário; Rodoanel; Modelo operacional; Sistema viário; Degradação do ambiente construído.

\section{BELTWAY, RING ROAD OR PERIMETER AVENUES?}

\begin{abstract}
This article intends to discuss the functionality of a road transportation complex, the ring road with its operational variations. Using as an example the Rodoanel Mário Covas, built in São Paulo Metropolitan Region, will show how the adoption of an inadequate operational model can compromise its performance and degrade the built environment.
\end{abstract}

Keywords: Beltway; Ring Road; Operating Model; Road System; Degradation of built environment. 


\section{INTRODUÇÃO}

Com o atual estado de saturação dos sistemas viários urbanos e metropolitanos, muitas cidades, de médio e grande porte tem se voltado para soluções que pretendem resolver o problema do transporte de pessoas e cargas, sendo a solução mais comum a implantação de anéis viários.

No entanto, deve-se entender, antes da proposição de uma solução que invariavelmente apresenta elevados custos diretos e indiretos, qual a vocação real de cada um dos sistemas viários, e quais os ônus gerados, para que essas obras viárias não apresentem uma baixa eficiência ou mesmo sejam ineficazes.

Assim, é importante entender realmente como, sob o título genérico de anel viário, diversas soluções, tecnicamente muito diferentes, dialogam com o espaço urbano que se pretende ordenar ou recuperar.

Nessa análise, será utilizado como exemplo o Rodoanel Mário Covas, que atende a região metropolitana da Grande São Paulo.

\section{OBJETIVOS A SEREM ATENDIDOS POR UM SISTEMA DE TRANSPORTES}

Todo sistema de transporte deve ser pensado, projetado e executado com um objetivo bem claro em mente. Note-se que o primeiro termo utilizado é "pensado", pois se deve considerar que, principalmente no ambiente antropizado, é essencial se imaginar como o sistema deve funcionar.

Esse aspecto se torna mais complexo quando se entende que um sistema de transporte pode privilegiar diversos pontos, como o transporte coletivo, o transporte individual ou o transporte de mercadorias, mas nunca irá atender de forma otimizada a todos.

Da mesma forma, as vias implantadas, conforme se define o seu sistema operacional, tanto podem causar integração como a segregação de áreas urbanas, na sua zona de influência.

É interessante notar que quando se discute a implantação de uma obra viária, nas audiências públicas dificilmente se discute o sistema operacional da via, como se isso 
fosse um fato inconteste, e não um elemento passível de discussão.

Tome-se como exemplo o Rodoanel Mário Covas. É interessante notar que seu projeto e implantação ficou a cargo da DERSA, uma autarquia com grande experiência em projetar e implantar estradas de alto desempenho, classificadas, no jargão da área, como estradas Classe 0 . Mais adiante essa classificação será melhor esmiuçada.

Quando da apresentação do projeto ao público em geral, foi dito que o grande objetivo do rodoanel seria desviar o trânsito de passagem pela região metropolitana de São Paulo, conectando as estradas que afluem à região metropolitana e permitindo a passagem desse volume de tráfego de forma segregada, não sobrecarregando mais o sistema urbano interno a esse anel. Dentro dessa lógica, a solução natural é sempre uma rodovia Classe 0 , pois ela se destina a ligar pontos relativamente distantes de forma rápida, sendo previstas velocidades de deslocamento superiores a $100 \mathrm{~km} / \mathrm{h}$, para o relevo no entorno de São Paulo.

No entanto, mesmo com a implantação agora de grande parte desse rodoanel, não se verifica uma melhora significativa no tráfego urbano na região metropolitana, com recordes de congestionamentos sendo batidos diariamente.

Então, em uma análise direta, é possível afirmar que o objetivo pretendido com essa obra viária não está sendo realmente atendido. Na verdade, é simples de se compreender a falha na proposta: na proposta do rodoanel, parte-se da premissa que o grande problema do tráfego das vias principais da região metropolitana é o tráfego de passagem.

No entanto, analisando-se todos os dados disponíveis sobre a região metropolitana da grande São Paulo se verifica que um dos grandes focos de consumo de bens, gêneros alimentícios e combustíveis, no país, para se citar apenas alguns dos elementos que fazem parte das necessidades básicas da civilização moderna, está na própria região metropolitana, com seus mais de 20 milhões de habitantes, ou aproximadamente $50 \%$ da população do Estado de São Paulo.

Para se entender melhor o que isso significa, segundo o IBGE, a população apenas da cidade de São Paulo, em 2013, já era estimada em quase 12 milhões de habitantes, com um IDHM de 0,805 , sendo nela gerados aproximadamente $25 \%$ do PIB do Brasil. 
Considerando esses fatos, compreende-se que o grande problema é que muitos produtos têm que adentrar à região metropolitana, para abastecer a população e permitir que ela desenvolva sua intensa atividade produtiva, ou seja, o sistema interno de distribuição de bens e pessoas é que se encontra sobrecarregado.

Dessa forma, afirmar que a implantação do Rodoanel Mário Covas, com sua forma e sistema operacional propostos, causa um impacto significativo no alívio do trânsito da região metropolitana, ao menos proporcional ao investimento feito, é ignorar tais dados, pois a classe viária adotada não apresenta vantagens quando o objetivo é atender a grandes volumes de tráfego, pois isso ocorre em rodovias quando a velocidade está em uma faixa próxima a $50 \mathrm{~km} / \mathrm{h}$, no Nível de Serviço E, como também, pelo número restrito de acessos, ela não permite um sistema local de distribuição de pessoas e mercadorias, além de a tornar extremamente vulnerável a bloqueios localizados que venham a ocorrer por diversos fatores.

Assim, sob essa análise, para que serve uma rodovia Classe 0 e que outras opções poderiam ser consideradas na solução do problema?

\section{TIPOS E CLASSES DE VIAS E SEU DIÁLOGO COM A MALHA VIÁRIA URBANA}

É interessante, para qualquer estudioso que queira entender como funciona uma cidade, conhecer determinadas características das vias inseridas tanto na área urbana como no seu entorno.

Neste caso específico, pode-se considerar que as características mais importantes são:

- Velocidade diretriz

- Acessibilidade

- Capacidade da via

A velocidade diretriz elevada, na faixa igual ou superior a $100 \mathrm{~km} / \mathrm{h}$, como prevista na Classe 0 , assegura logicamente um deslocamento mais rápido ente pontos distantes. No entanto, quando nessa via é operado um sistema de transporte urbano baseado em ônibus, essa mesma velocidade conflita com a operação dos coletivos, que entram e saem do fluxo para atender as paradas regulares, apresentando então velocidades médias muito inferiores ao previsto em projeto. 
Isso gera uma turbulência que diminui a eficiência do sistema viário, nessa classe de via, e passa a não justificar a sua adoção em regiões metropolitanas.

Quanto à acessibilidade, este é um forte indicativo de como se pretende o diálogo da via com o entorno.

Quando se pretende o emprego de vias com características rodoviárias, como no caso do Rodoanel Mário Covas, onde o próprio nome já indica a solução adotada, temos a seguinte classificação:

Tabela 1: Classes das rodovias no Brasil

\begin{tabular}{|c|c|c|}
\hline Classe de projeto & Características & Critério de classificação técnica \\
\hline 0 & $\begin{array}{l}\text { Via Expressa - controle total } \\
\text { de acessos }\end{array}$ & Decisão administrativa \\
\hline I A & $\begin{array}{l}\text { Pista Dupla - controle parcial } \\
\text { de acessos }\end{array}$ & $\begin{array}{l}\text { O volume de tráfego previsto reduziria o nível } \\
\text { de serviço em uma rodovia de pista simples } \\
\text { abaixo do nível "C" }\end{array}$ \\
\hline I B & Pista Simples & $\begin{array}{l}\text { Volume horário de projeto - VHP > } 200 \\
\text { Volume médio diário - VMD > } 1400\end{array}$ \\
\hline II & Pista Simples & Volume médio diário - $700<$ VMD $<1400$ \\
\hline III & Pista Simples & Volume médio diário $-300<$ VMD $<700$ \\
\hline IV & Pista Simples & Volume médio diário - VMD $<300$ \\
\hline
\end{tabular}

Nas estradas Classe 0, por se pretender um rápido deslocamento entre pontos relativamente distantes, existe o controle total de acessos, sendo estes muito espaçados e exigindo uma ocupação espacial significativa, pelas altas velocidades previstas também nas alças de acesso. É comum, em estradas dessa classe, que as vias a ela conectadas sejam sobrecarregadas, pela falta de opção.

Já em rodovias de classes inferiores, podemos ter controle parcial de acessos, nas Classes I e II, e regulamentação de acessos, nas Classes III e IV. Nestes casos, a velocidade operacional da via é diretamente afetada, mas a saturação das vias de 
acesso não é um fenômeno tão frequente. Pode-se dizer que são vias mais permeáveis, pois o maior número de acessos permite a utilização de vias paralelas quando o sistema principal está sobrecarregado ou sofre uma interrupção.

Já o volume de veículos que pode ser atendido por uma via está relacionado com o nível de serviço em que ela opera, pois a maior capacidade volumétrica de uma via ocorre em rodovias quando a velocidade está em uma faixa próxima a $50 \mathrm{~km} / \mathrm{h}$, no Nível de Serviço E, e esse nível de serviço é afetado, entre outras coisas, pelo número de acessos e seu traçado, propício ou não à indexação de novos fluxos, que causam interferência na operação do sistema.

Dessa forma, se verifica que, ao contrário do que se imagina, não é garantindo maiores velocidade de deslocamento que se obtém um maior volume de veículos em um sistema viário.

Outro aspecto a ser analisado é a questão dos cruzamentos, elementos essenciais em áreas urbanas.

Em um modelo rodoviário, seja uma rodovia de Classe 0 ou Classe I, não são previstos cruzamentos em nível. No entanto, se forem considerada a classificação abaixo apresentadas, verifica-se que nos tipos mais usuais de vias urbanas, o cruzamento em nível é previsto.

Para vias urbanas, a classificação usual simplificada é a seguinte:

- Vias expressas - tem várias faixas de tráfego, e apresentam controle de acesso ou um sistema operacional hierarquizado. Não se prevê cruzamento em nível.

- Avenidas - tem várias faixas de tráfego, mas com um controle menor dos acessos, normalmente não tendo um sistema operacional hierarquizado. São previstos cruzamentos em nível, com controle de passagem.

- Ruas - vias de características locais, com normalmente duas faixas de tráfego, podendo ter uma ou duas mão de direção, com cruzamentos em nível e normalmente com definição de preferenciais.

Apesar de se entender que uma Via Expressa possui características operacionais compatíveis com uma rodovia Classe 0 , deve-se entender que normalmente essa via 
possui uma hierarquização de faixas, que podem ser separadas fisicamente, compondo um sistema de alta velocidade de deslocamento, normalmente as faixas centrais, $\mathrm{e}$ as faixas locais, um sistema de baixa velocidade, sendo que estas proporcionam uma conexão com as vias urbanas da região. A conexão dos dois sistemas dentro da via é feito de forma espaçada, e muitas vezes operado diretamente nos horários de pico.

Já as avenidas e as ruas possuem características tipicamente urbanas, pois permitem o acesso ao longo de todo o seu desenvolvimento, como também permitem o cruzamento de nível, de forma controlada. Essas características acarretam uma perda de velocidade operacional, como também, nos horários de pico, uma perda volumétrica. No entanto, são os dispositivos de maior permeabilidade possível dentro da área urbana.

Também, se forem considerados os pedestres, um elemento de transporte de grande peso em qualquer análise de sistemas de transporte urbano, só existe a conexão adequada destes com as avenidas e ruas, em um sistema de calçadas coaxiais às pistas para veículos automotores. Pode-se afirmar que as outras tipologias são extremamente hostis ao ser humano na sua forma pedestre.

\section{INTEGRAÇÃO OU SEGREGAÇÃO}

Além das características operacionais das vias, e seu diálogo direto com a malha viária urbana, há de se considerar a sua interação com o ambiente continho na sua área de influência direta e indireta.

É interessante considerar que existem dois efeitos opostos que podem ser causados pela adoção de um ou outro tipo de via. São eles:

- Integração

- Segregação

A integração se dá quando é adotado um modelo de via que permite acesso direto ou pouco espaçado, muitas conexões de vias, e o cruzamento em nível. É o típico modelo urbano, em que é adotado o modelo de avenidas e ruas, em um distribuição hierarquizada, e apresenta uma área de influência direta de grande largura, e esta quase que se sobrepõe à área de influência indireta. 
Essa liberdade de acesso favorece a ocupação ao longo do anel viário, favorecendo o fechamento de vazios urbanos e quando implantado em um ambiente já antropizado, apresenta menor impacto no seu entorno.

Já quando se considera o incremento no fluxo de veículos, o impacto não é tão significativo se as conexões com outras vias permitir uma diluição desse fluxo nos momentos de pico, daí a necessidade da operação efetiva do sistema viário nesses horários.

No entanto, quando adotado em áreas ainda pouco ou não antropizadas, essa mesma permeabilidade pode ser um forte elemento indutor à ocupação do seu entorno, seja ela regular ou irregular, sendo assim um elemento de estímulo à especulação imobiliária, em níveis muito superiores ao que ocorre em áreas com maiores taxas de ocupação.

Se for considerado o modelo genérico apresentado na figura 1, representativo de uma área urbana com desenvolvimento radial e concêntrico, o efeito de integração, com a marcação das áreas que sofrem o estímulo da ocupação pode ser visto na figura 2.

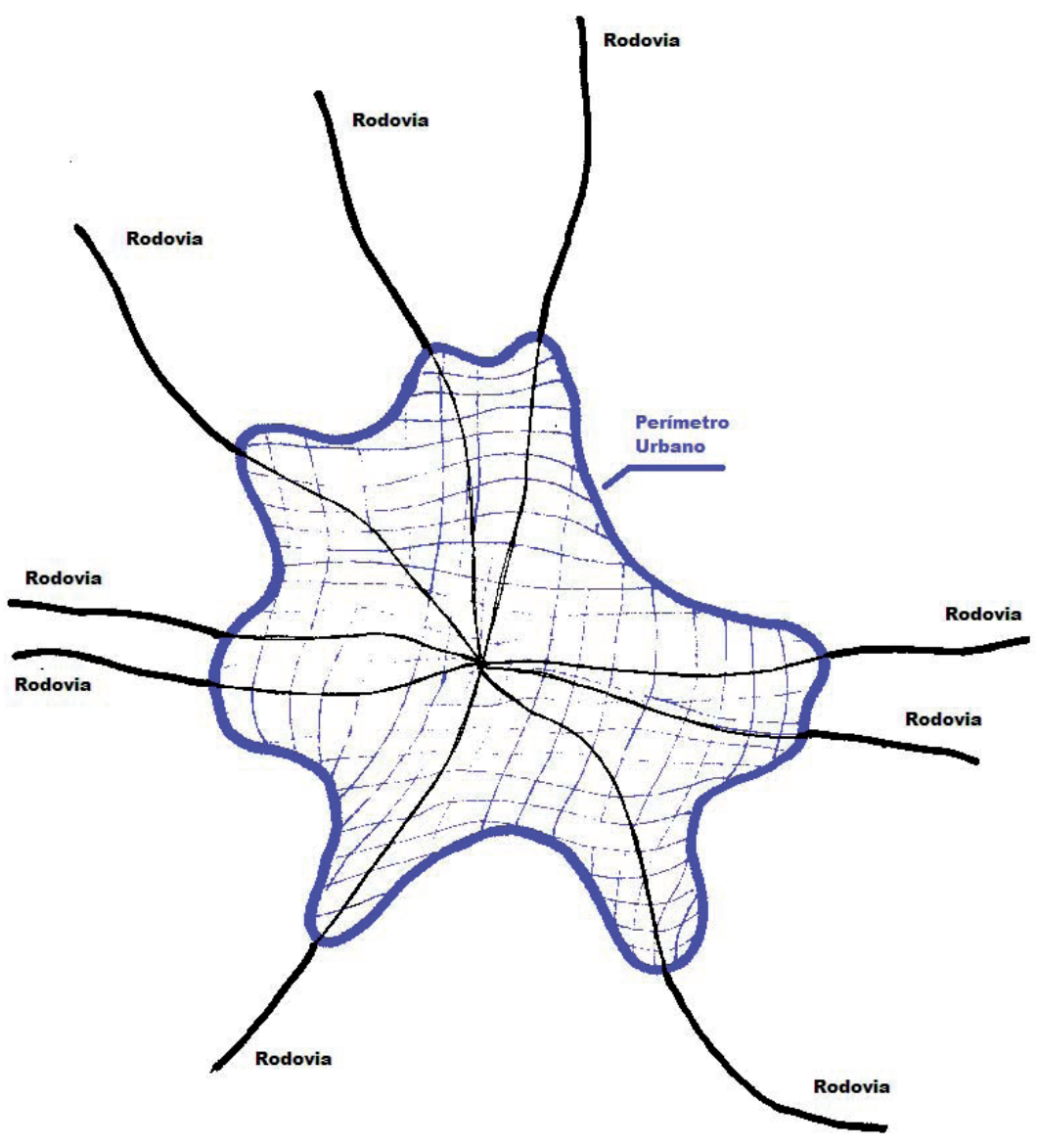

Figura 1: modelo genérico de uma área urbana, com desenvolvimento radial, em que as vias originais se transformam em avenidas dentro do perímetro urbano, enquanto que fora dele mantém as características rodoviárias. 


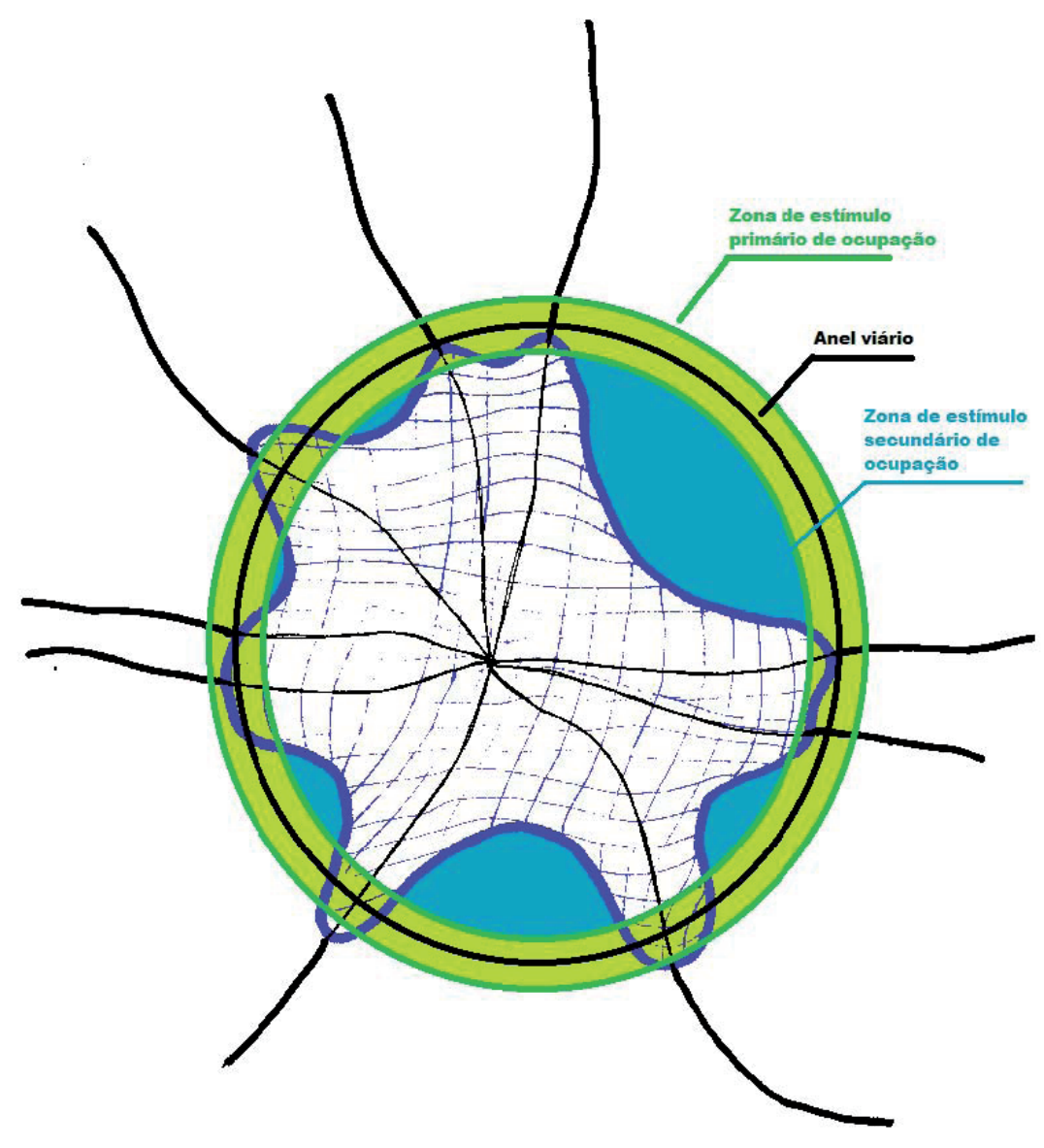

Figura 2: na adoção de um modelo viário urbano, em que o anel viário é composto por avenidas, é de se esperar um grande estímulo à ocupação ao longo de toda essa via, e, com o decorrer do tempo, o fechamento de vazios entre o perímetro urbano original e o anel viário.

O efeito contrário da integração é a segregação. Ela ocorre quando a via se torna uma barreira física à estrutura urbana, por suas características rodoviárias, propiciando poucos acessos, e não permitindo cruzamentos de nível. Como cruzamentos em desnível são caros e ambientalmente impactantes, tanto pelo seu porte como pela área que ocupam, estes não são adotados em todas as vias urbanas interceptadas, apenas naquelas com fluxo de veículos significativo, o que naturalmente provoca sua sobrecarga, enquanto que as de menor fluxo, interceptadas, se tornam becos. Essa é uma das suas principais características, e esse sistema apresenta uma área de influência direta de pequena largura, mas uma área de influência indireta de grande profundidade, devido ao efeito provocado nas vias de conexão.

Devido a essas particularidades, a área urbana lindeira a uma via com essa característica de bloqueio físico tende à apresentar uma degradação do ambiente construído, como pode ser constatado em diversas obras em São Paulo, sendo o caso mais conhecido as áreas contíguas às marginais Tietê e Pinheiros, com pouca vias muito valorizadas para comércio mas mesmo essas pouco utilizadas para habitações, sendo ambientes hostis aos pedestres. 


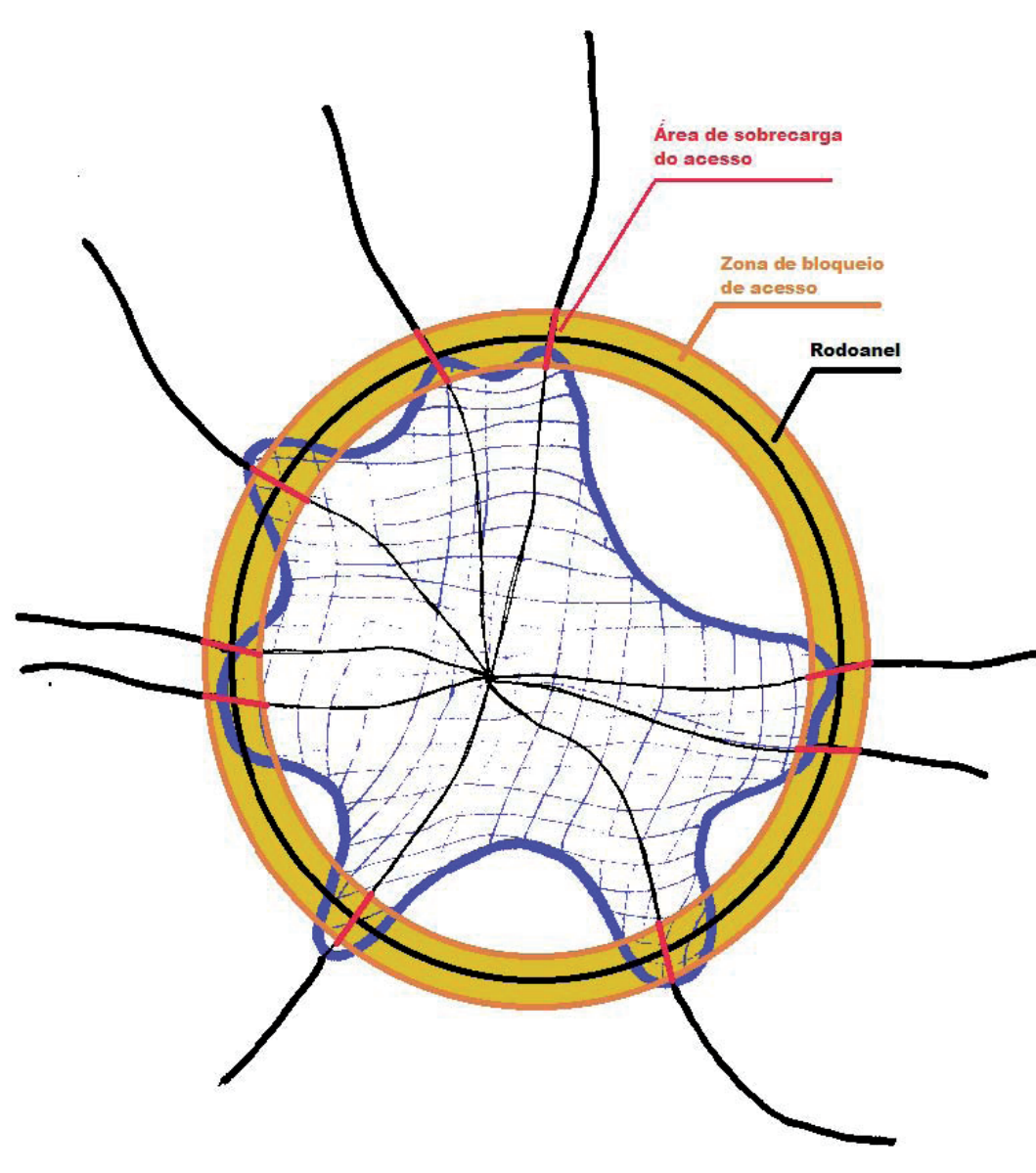

Por outro lado, esse efeito de bloqueio pode ser utilizado de forma positiva quando se pretende preservar uma área de ações especulativas ou de ocupação desordenada.

Esse efeito pode ser visto na figura 3.

Figura 3: na adoção de um modelo rodoviário, co cruzamentos em desnível e poucos acessos, as vias de conexão entre o rodoanel e a malha urbana são sobrecarregados, enquanto as outras vias são bloqueadas, perdendo volume de tráfego, sendo então subutilizadas. Ocorre ainda a manutenção dos vazios urbanos nas áreas lindeiras à via.

\section{POSSIBILIDADE DE UTILIZAÇÃO DOS EFEITOS MODELADORES}

Se for considerado que os efeitos causados pelos sistemas viários, no ambiente compreendido pelas suas zonas de influência direta e indireta, se bem aplicados, são ferramentas para a modelagem da estrutura urbanas, é possível efetuar o planejamento de sistemas viários não apenas sob o ponto de vista funcional direto, ou seja, entendendo que uma via não é apenas um condutor de veículos.

Sob essa ótica, no planejamento urbano é necessário analisar o impacto causado pela escolha do sistema operacional viário, para então estabelecer qual melhor se adequa ao tipo de ocupação pretendida para cada área.

Retornando ao Rodoanel Mário Covas, é interessante notar a sua homogeneidade operacional, ou seja, não importa por que tipo de área ele passe, sempre apresenta o mesmo padrão rodoviário, neste caso o de uma rodovia Classe 0 . 
No entanto, analisando sob a ótica de ocupação espacial, verifica-se que áreas completamente díspares são por ele cruzadas. Vão desde áreas já intensamente ocupadas até áreas de preservação ambiental. Isso significa que o rodoanel foi projetado tem como foco apenas a passagem de veículos, de forma desconectada com o sistema viário urbano, devido à adoção de uma premissa de projeto equivocada, desconsiderando-se assim a sua capacidade modeladora do ambiente urbano. Pode-se dizer que esse tipo de projeto sofre de Síndrome de Magalhães (ou Síndrome de Drake), pois tem como objetivo a circunavegação de um ambiente, e não a interação com ele.

Se o projeto seguisse uma lógica de planejamento urbano, nos estudos iniciais já deveria ser feita a sua divisão em segmentos homogêneos, ou seja, deveriam ser identificadas todas as áreas segundo suas características de ocupação urbana ou necessidades preservacionistas, entre outras que podem ser elencadas no ambiente antropizado e seu entorno.

A partir dessa identificação, seria necessário analisar qual o sistema operacional que melhor se adequa a cada segmento homogêneo. Como exemplo pode-se considerar que uma região já urbanizada, dotada de uma malha de ruas e avenidas significativo, sem concentração expressiva do fluxo viário em nenhum eixo, pode ter seu segmento do anel viário constituído por uma avenida de múltiplas faixas, apresentando menor velocidade diretriz e maior volume de interferências, enquanto uma região que se pretende preservar da ocupação pode ter seu segmento do anel constituído por uma rodovia, com poucos ou nenhum acesso e com maior velocidade diretriz e menor volume de interferências, o que permite a adoção de um menor numero de faixas.

Considerando ainda que nas vias urbanas interagem pedestres, bicicletas, motocicletas, carros de passeios, onibus e caminhões, sendo os veículos automotores de diversos portes e potências, um bonus gerado por essa abordagem, em que se analisa cada segmento homogêneo, seria a análise específica sobre quais e como esses elementos integarem nesse segmento, sendo gerando então um modelo operacional que tivesse como um dos seus objetivos básicos a diminuição dos conflitos entre esses sistemas de deslocamento de pessoas e cargas.

Caso o anel viário fosse planejado dessa forma, com uma análise meticulosa de como a sua presença interage com o ambiente em que se insere, pode-se afirmar que seriam obtidos os seguintes efeitos: 
- Ordenação do sistema viário

- Diminução do número de acidentes e interrupções de fluxo

- Valorização do ambiente urbano

- Diminuição de conflitos sociais

- Preservação de ambientes naturais

- Otimização de recursos públicos

É necessário entender que, devido a características operacionais inescapáveis, é necessário que esses segmentos homogêneos tenham um determinado comprimento, de pelo menos alguns quilômetros, para que não haja uma mudança muito frequente nas características das vias, sendo necessário ainda que se utilizem zonas de transição, para garantir a segurança dos usuários do sistema.

Por fim, é necessário entender que não é apenas um dispositivo de transporte que irá resolver ou problemas de transporte de uma área urbana, mas a conjugação de diversos meios e modais, sendo que cada um deles apresenta eficiência em um determinado nicho operacional, podendo se tornar um problema quando opera fora dele.

\section{CONCLUSÃO}

A análise apresentada, que não pretende de forma alguma esgotar o assunto, objetivou demonstrar que, quando uma obra de infraestutura é abordado apenas com uma visão técnica restrita, a avaliação deficiente tanto dos problemas como da capacidade transformadora dos sitemas de transportes leva a uma perda significativa de seus impactos positivos, enquanto que podem ser gerados novos problemas, principalmente de ordem social.

No caso específico de obras viárias inseridas no ambiente urbano, nota-se um elemento recorrente, a abordagem rodoviária, extremanente tecnicista, com uma preocupação absoluta quanto à eficiência dos veículos automotores.

É interessante notar que, quase sem exceção, todas as obras com essa abordagem são apresentadas pelos gestores como a solução do problema, dos problemas ou de todos os problemas, como um moderno Deus ex machina, mas ao final pouco impacto positivo apresentam, por não considerar, ou então minimizar a interação 
necessária com o ambiente em que se inserem, além de desprezar a interação adequada com outros sistemas de transporte urbano. É o que define como falha básica de diagnóstico.

O outro problema verificado é que essa forma de planejar parece ignorar que, principalmente em áreas urbanas, deve-se ter como ponto de partida e referência permanente o homem, elemento para o qual se destina esse ambiente, e soluções que não apresentem, dentro dessa referência, ganhos reais, a curto, médio ou a longo prazo devem ser descartadas, pois significam um desperdício de recursos, sempre finitos em qualquer esfera de governo

\section{REFERÊNCIAS BIBLIOGRÁFICAS}

ALVARES JUNIOR, Olímpio de Melo. Aspectos ambientais do trânsito de veículos automotores. Guaratinguetá, GEIPOT, 1993.

CAMPOS FILHO, Cândido Malta. Cidades Brasileiras: seu controle ou o caos: o que os cidadãos devem fazer para a humanização das cidades no Brasil. 2. ed.. São Paulo, Studio Nobel, 1992.

FERRARI, CÉLSON. Curso de Planejamento Municipal Integrado - Urbanismo. $2^{\text {a }}$ Ed. São Paulo, Livraria Pioneira Editora, 1979.

FRANCO, Maria de Assunção Ribeiro. Planejamento ambiental para a cidade sustentável. São Paulo: Annablume: FAPESP, 2000.

FRANCO, Maria de Assunção Ribeiro. Desenho Ambiental: uma indrodução à arquitetura da paisagem com o paradigma ecológico. São Paulo. Annablume, 1997.

HIGHWAY RESEARCH BOARD. Highway capacity manual 1965. Washington, D.C.. Highway Research Board, 1966.

LANGENBUCH, J.R.. Estruturação da Grande São Paulo. Rio de Janeiro, IBGE, 1971.

LIDDELL HART, Basil Henry. Strategy. 2. rev. ed. New York: Penguin Books, 1999. 
LOVEJOY, Derek, coordenador et al. Land use and landscape planning. Leonard Hill Books, 1973.

MASCARÓ, Juan Luis; CLARO, Anderson e SCHNEIDER, Ingrid Elisabeth. A evolução dos sistemas de construção como o desenvolvimento econômico: uma visão retrospectiva. São Paulo, FAUUSP, 1978.

McHARG, Ian L.. Design with nature. Nova lorque, The American Museum of Natural History, The Natural History Press, 1969.

VASCONCELOS, Eduardo Alcântara de. Circular é preciso, viver não é preciso: a história do trânsito na cidade de São Paulo. São Paulo, Annablume: FAPESP, 1999. 